\title{
Phase I trial to evaluate the addition of alisertib to fulvestrant in women with endocrine-resistant, ER+ metastatic breast cancer
}

\author{
Tufia C. Haddad' 1 (1) - Antonino D'Assoro ${ }^{2}$. Vera Suman ${ }^{3} \cdot$ Mateusz Opyrchal $^{4} \cdot$ Prema Peethambaram $^{1}$. \\ Minetta C. Liu ${ }^{1,5} \cdot$ Matthew P. Goetz $^{1}$. James N. Ingle ${ }^{1}$
}

Received: 30 November 2017 / Accepted: 7 December 2017 / Published online: 30 December 2017

(C) The Author(s) 2017. This article is an open access publication

\begin{abstract}
Purpose In estrogen receptor-positive (ER+) breast cancer models, activation of Aurora A kinase (AURKA) is associated with downregulation of ER $\alpha$ expression and resistance to endocrine therapy. Alisertib is an oral selective inhibitor of AURKA. The primary objectives of this phase I trial were to determine the recommended phase II dose (RP2D) and evaluate the toxicities and clinical activity of alisertib combined with fulvestrant in patients with ER+ metastatic breast cancer (MBC). Methods In this standard $3+3$ dose-escalation phase I study, postmenopausal patients with endocrine-resistant, ER+ MBC previously treated with endocrine therapy were assigned to one of two dose levels of alisertib (40 or $50 \mathrm{mg}$ ) in combination with fixed-dose fulvestrant.

Results Ten patients enrolled, of which nine were evaluable for the primary endpoint. The median patient age was 59. All patients had secondary (acquired) endocrine resistance, and all had received prior aromatase inhibitor. Six had experienced disease progression on fulvestrant. There were no severe (grade 3+) toxicities reported during cycle 1 at either dose level. The median progression-free survival time was 12.4 months (95\% CI 5.3-not met), and the 6-month clinical benefit rate was $77.8 \%$ (95\% CI 40.0-87.2\%).

Conclusions In patients with endocrine-resistant, ER+ MBC, alisertib in combination with fulvestrant was well tolerated. A favorable safety profile was observed. The RP2D is $50 \mathrm{mg}$ twice daily on days $1-3,8-10$, and $15-17$ of a 28 -day cycle with standard dose fulvestrant. Promising antitumor activity was observed, including activity among patients with prior progression on fulvestrant.
\end{abstract}

Keywords Aurora A kinase $\cdot$ Alisertib $\cdot$ Fulvestrant $\cdot$ Breast cancer $\cdot$ Estrogen receptor

Tufia C. Haddad

haddad.tufia@mayo.edu

1 Division of Medical Oncology, Mayo Clinic, 200 First Street S.W., Rochester, MN 55905, USA

2 Department of Biochemistry and Molecular Biology, Mayo Clinic, Rochester, MN, USA

3 Department of Biostatistics, Mayo Clinic, Rochester, MN, USA

4 Division of Oncology, Roswell Park Cancer Center, Buffalo, NY, USA

5 Department of Laboratory Medicine and Pathology, Mayo Clinic, Rochester, MN, USA

\section{Introduction}

Each year, approximately 1.2 million women worldwide are diagnosed with estrogen receptor-positive $(\mathrm{ER}+)$ breast cancer [1]. While 5 years of adjuvant endocrine therapy significantly reduces the risk of recurrence, the cumulative risk of a distant recurrence during years 5-14 ranges from 9.8\% for N0 (node-negative) disease to $27.7 \%$ for N2 (4-9 nodepositive) disease [2, 3].

Both de novo and acquired resistance to endocrine therapy remain a major clinical problem $[4,5]$. Although most endocrine-resistant breast tumors retain ER $\alpha$ expression, loss of ER $\alpha$ is a well-described mechanism of resistance associated with aggressive tumor behavior and poor clinical outcomes [4-9]. Currently, there are no FDA-approved approaches which reverse endocrine resistance associated with downregulation or loss of ER $\alpha$ expression. 
During tumor progression, deregulated activation of Aurora A kinase (AURKA) is functionally linked to epithelial-to-mesenchymal transition (EMT) reprogramming and expansion of a subpopulation of tumor-initiating cells harboring a $\mathrm{CD} 44^{+} / \mathrm{CD} 24^{\text {low/- }}$ phenotype [10-12]. These tumor-initiating cells have stem cell-like properties characterized by their capacity to self-renew, resist drug therapies, and promote distant metastases [13]. In luminal ER+ breast cancer models, activation of AURKA is required to induce EMT and clonal expansion of CD $44^{+} / \mathrm{CD} 24^{\text {low } /-}$ cells, thus driving tumor progression [14]. These cells are further characterized by loss of ER $\alpha$ protein expression and resistance to endocrine therapy [15]. Moreover, aberrant AURKA activity is required to induce the expression of SMAD5 and SOX2 $[14,15]$, two master transcription factors involved in the regulation of EMT and stemness reprogramming [16-19].

In translational studies, residual tumor specimens collected from women with operable ER+ breast cancer following neoadjuvant letrozole contain a significantly enriched $\mathrm{CD} 44^{+} / \mathrm{CD} 24^{\text {low/- }}$ subpopulation and upregulation of mesenchymal genes as compared to their pre-treatment tumor [20]. Kinase inhibitor screens in both endocrine-sensitive and endocrine-resistant cell lines identified AURKA as a potential treatment target in ER+ breast cancer [21, 22]. Moreover, in women with operable ER+ breast cancer treated with tamoxifen, both disease-free and overall survival (OS) were shorter among those with high levels of tumor expression of AURKA [21]. Similar findings from Siggelkow et al. demonstrated that high levels of tumor AURKA expression were associated with decreased metastasis-free survival in women with lymph node-negative breast cancer who had not received adjuvant chemotherapy [23]. Thus, this novel function of AURKA has untapped potential as a biomarker and therapeutic target for endocrine-resistant breast cancer.

In endocrine-resistant, ER+ breast cancer models, alisertib, a selective inhibitor of AURKA, was found to reverse stemness reprogramming and thereby restore the CD $44^{-} / \mathrm{CD} 24^{+}$phenotype, ER $\alpha$ expression, and sensitivity to endocrine therapy $[14,15]$. Moreover, alisertib was found to reduce cellular proliferation in tamoxifen-resistant cells, and this effect was enhanced with the addition of fulvestrant [15]. In summary, based on this preclinical and translational data, we hypothesized that inhibition of AURKA in endocrine-resistant breast cancer could lead to a new therapeutic strategy to restore endocrine sensitivity by targeting the $\mathrm{CD} 44^{+} / \mathrm{CD} 24^{\text {low/- }} / \mathrm{ER} \alpha^{\text {low/- }}$ tumor-initiating cells that promote endocrine resistance.

In the clinical development of alisertib, its safety and tolerability profile has been well defined at the recommended phase II dose (RP2D) of $50 \mathrm{mg}$ tablets orally twice daily on days 1-7 of a 21-day cycle [24, 25]. In a phase II trial of alisertib monotherapy at the RP2D, alisertib was associated with a 6-month clinical benefit rate $(\mathrm{CBR}=\mathrm{CR}+\mathrm{PR}+\mathrm{SD}$ for $\geq 6$ months) of $54 \%$ and median progression-free survival (PFS) of 7.9 months in those with heavily pre-treated, ER+/HER2-negative breast cancer $(n=26)$ [26]. Neutropenia (57\%) and leukopenia (36\%) were the most frequently reported severe toxicities among the 49 breast cancer patients enrolled [26]. An alternative 28-day, 'pulse dose' regimen with alisertib given days $1-3,8-10$, and $15-17$ was studied in combination with paclitaxel in a triple-negative breast cancer xenograft model, and it was associated with similar antitumor activity compared with the 7-day continuous schedule at the RP2D [27]. Previous studies modeling hematologic toxicity also predicted that the pulse dose regimen would decrease the incidence of dose-limiting neutropenia compared with a 7-day continuous schedule [28].

The primary objectives of this phase I trial were to evaluate the toxicities and clinical activity of alisertib with fulvestrant in patients with ER+ advanced breast cancer. The 'pulse dose' schedule of alisertib was pursued as its 28-day schedule was compatible with the standard 28 -day schedule of fulvestrant.

\section{Methods}

\section{Patients}

Eligible patients were postmenopausal women age $\geq 18$ years who had histologically confirmed metastatic or locally advanced, unresectable breast cancer that was estrogen and/or progesterone receptor positive and had progressed on at least one prior line of endocrine therapy. Unlimited prior endocrine therapies were allowed. Prior fulvestrant was not mandated. One prior line of chemotherapy was required in either the (neo)adjuvant or metastatic setting, and no more than 2 prior lines of chemotherapy were allowed in the metastatic setting. An Eastern Cooperative Oncology Group (ECOG) performance status $\leq 1$, life expectancy of $\geq 4$ months, and adequate hematologic, hepatic, and renal function were required. Measurable or non-measurable disease per RECIST criteria (v.1.1) and stable treated CNS metastases were allowed. Patients necessitating routine use of proton pump inhibitors, H2-blockers, or pancreatic enzymes were ineligible as concurrent administration of these medications with alisertib has been associated with increased alisertib exposure. This study was performed after approval by the Mayo Institutional Review Board in accordance with assurances filed with and approved by the Department of Health and Human Services. All patients provided written informed consent. 


\section{Study design}

A $3+3$ phase I clinical trial was conducted to determine if the previously established $50 \mathrm{mg}$ twice daily RP2D of alisertib (on a 21-day schedule) would be tolerable when administered on the 'pulse dose' 28-day schedule in combination with standard dose fulvestrant. This schedule was selected as it was deemed compatible with the rigid 28-day schedule of fulvestrant. Alisertib was administered twice daily by mouth on days $1-3,8-10$, and $15-17$ of each cycle. Two dose levels were planned for evaluation ( 40 and $50 \mathrm{mg}$ ) as previous studies with the 21-day schedule showed substantial toxicity above the $50 \mathrm{mg}$ dose level. The starting dose level was $40 \mathrm{mg}$. Fulvestrant was given as $500 \mathrm{mg}$ IM on days $1 \& 15$ of cycle 1 and day 1 of all subsequent cycles. Adverse events and safety laboratory studies were recorded at the end of each treatment cycle. As hair loss has been associated with alisertib, it was also self-assessed at the end of each treatment cycle using the Modified WHO scale [29]. Tumor assessments occurred after every 2 cycles of therapy.

\section{Statistical analysis}

The decision to dose escalate/de-escalate was based on the number and severity of the toxicities that developed during the first cycle of treatment.

Dose-limiting toxicities (DLT) included the following: febrile neutropenia with grade $\geq 3$ neutropenia; grade $\geq 4$ anemia; grade 3 neutropenia lasting 5 or more days; grade $\geq 4$ neutropenia; grade 3 thrombocytopenia with grade $\geq 3$ bleeding; grade $\geq 4$ thrombocytopenia; grade $\geq 3$ acute kidney injury, somnolence, oral mucositis, or other non-hematologic toxicity; and a delay in treatment of greater than 2 weeks due to toxicity.

If 2 or more of the 6 patients treated at the $40 \mathrm{mg}$ dose develop a DLT, the next cohort of 3 patients was to be enrolled at the $30 \mathrm{mg}$ dose level. If at most 0 out of 3 patients or 1 out of 6 patients developed a DLT at the $40 \mathrm{mg}$, the next cohort of 3 patients was enrolled at the $50 \mathrm{mg}$ dose level. No other dose levels were considered.

\section{Study endpoints and assessments}

All patients meeting the eligibility criteria who provided written informed consent and began protocol-directed therapy were included in the analysis of the safety and clinical outcome data. The data lock for this report was October 23, 2017.

The primary endpoint of this trial was to determine if the previously established RP2D of alisertib $(50 \mathrm{mg})$ on 21-day schedule was tolerable when administered on a 'pulse dose' 28-day schedule in combination with standard dose of fulvestrant. The RP2D of alisertib in combination with fulvestrant was defined as the highest dose level, among those under consideration (up to $50 \mathrm{mg}$ ), where at most 1 of 6 patients develops a DLT.

Tumor response was defined by RECIST criteria (v. 1.1) for a partial or complete response (PR or CR) on two consecutive evaluations at least 8 weeks apart. Duration of tumor response was the time from registration to disease progression. PFS was the time from registration to documentation of the first of the following events: local, regional, or distant recurrence, diagnosis of contralateral breast disease, diagnosis of a second primary, or death due to any cause. Survival time was the time from registration to death due to any cause. The distribution of event times was estimated using the Kaplan-Meier method.

\section{Correlative studies}

Archived tumor tissue samples from either the primary tumor or a metastatic site were available for 7 of the 9 evaluable subjects. These tissue samples will be used for analysis of ER $\alpha$, phosphorylated (p) pAURKA, pSMAD5, and pSOX2 expression. This work is ongoing in support of the follow-up phase II study.

\section{Results}

\section{Study population}

From September 8, 2014 to April 2, 2015, 10 women were enrolled ( 3 at $40 \mathrm{mg}$ dose and 7 at $50 \mathrm{mg}$ dose). One patient entered at the $50 \mathrm{mg}$ dose level was found to be ineligible and replaced as she was on a proton pump inhibitor at the time of registration. Patient and tumor baseline characteristics of the remaining nine patients are presented in Table 1 .

The median patient age was 59 (range $48-73$ years). All patients had secondary endocrine resistance defined by the ESO-ESMO guidelines as recurrence on but after the first 2 years of adjuvant endocrine therapy, or recurrence within 12 months of completing adjuvant endocrine therapy, or metastatic disease progression occurring on but $\geq 6$ months after initiating first-line endocrine therapy [30]. Prior endocrine treatments included an aromatase inhibitor (100\%), fulvestrant (66.7\%), tamoxifen (55.6\%), and everolimusbased endocrine regimen (55.6\%). Four patients had received anthracycline and taxane-based chemotherapy in the adjuvant setting, and six patients $(66.7 \%)$ had received chemotherapy in the metastatic setting. Six patients $(67 \%)$ had visceral metastatic disease, and three patients (33\%) had bone-only metastases. Three patients (33\%) had measurable disease per RECIST criteria (v. 1.1). 
Table 1 Patient baseline characteristics

\begin{tabular}{|c|c|}
\hline Baseline characteristics & $\begin{array}{l}\text { Evaluable patients } \\
N=9\end{array}$ \\
\hline Median age (range) & $\begin{array}{l}59 \text { years } \\
(48-73 \text { years })\end{array}$ \\
\hline \multicolumn{2}{|l|}{ ECOG performance status } \\
\hline 0 & $4(44.4 \%)$ \\
\hline 1 & $5(55.5 \%)$ \\
\hline \multicolumn{2}{|l|}{ Histology } \\
\hline Ductal & $6(66.7 \%)$ \\
\hline Lobular & $3(33.3 \%)$ \\
\hline \multicolumn{2}{|c|}{ Specimen used for ER, PR, and HER2 testing collected at } \\
\hline Primary diagnosis & $3(33.3 \%)$ \\
\hline Previous metastatic episode & $5(55.6 \%)$ \\
\hline Current metastatic episode & $1(11.1 \%)$ \\
\hline \multicolumn{2}{|l|}{ Biomarker status } \\
\hline ER-positive & $9(100 \%)$ \\
\hline PR-positive & $9(100 \%)$ \\
\hline HER2-negative & $9(100 \%)$ \\
\hline \multicolumn{2}{|c|}{ Metastatic relapse on or within 1-year completion of adjuvant endocrine therapy } \\
\hline Yes & $5(55.6 \%)$ \\
\hline No & $4(44.4 \%)$ \\
\hline \multicolumn{2}{|c|}{ Lines of hormonal therapy in the metastatic setting } \\
\hline 0 & $1(11.1 \%)$ \\
\hline 1 & $2(22.2 \%)$ \\
\hline 2 & $2(22.2 \%)$ \\
\hline 3 or more & $4(44.4 \%)$ \\
\hline \multicolumn{2}{|c|}{ Prior hormonal therapies in the metastatic setting } \\
\hline Non-steroidal AI & $8(88.9 \%)$ \\
\hline Fulvestrant & $6(66.7 \%)$ \\
\hline Exemestane + everolimus & $5(55.6 \%)$ \\
\hline Tamoxifen & $2(22.2 \%)$ \\
\hline Z-Endoxifen & $2(22.2 \%)$ \\
\hline \multicolumn{2}{|c|}{ Lines of chemotherapy in metastatic setting } \\
\hline 0 & $3(33.3 \%)$ \\
\hline 1 & $4(44.4 \%)$ \\
\hline 2 & $2(22.2 \%)$ \\
\hline \multicolumn{2}{|l|}{ Hair loss } \\
\hline None & $6(66.7 \%)$ \\
\hline$\leq 10 \%$ & $2(22.2 \%)$ \\
\hline$>75 \%$ & $1(11.1 \%)$ \\
\hline \multicolumn{2}{|l|}{ Pre-treatment toxicities } \\
\hline Grade 1 anemia & $3(33.3 \%)$ \\
\hline Grade 1 fatigue & $3(33.3 \%)$ \\
\hline Grade 1 neutropenia & $1(11.1 \%)$ \\
\hline Grade 1 kidney injury & $1(11.1 \%)$ \\
\hline
\end{tabular}

\section{Dose escalation and RP2D determination}

Three patients enrolled onto the $40 \mathrm{mg}$ dose level of alisertib and completed their first cycle of treatment without developing a DLT. Thus, the next cohort of 3 patients was enrolled onto the $50 \mathrm{mg}$ dose level of alisertib. None of these 3 patients developed a DLT during cycle 1, so an additional 3 patients were enrolled onto the $50 \mathrm{mg}$ dose level of alisertib. As none of the 6 patients enrolled onto the $50 \mathrm{mg}$ dose level of alisertib developed a DLT during their first cycle of treatment, $50 \mathrm{mg}$ twice daily of alisertib 
is the RP2D on a 28-day schedule when used in combination with standard dosing of fulvestrant.

\section{Safety}

Grade 2 toxicities reported during the first cycle of treatment included: neutropenia (44.4\%), leukopenia (22.2\%), anemia (11.1\%), diarrhea (11.1\%), and alopecia (11.1\%). There were no grade 3 or 4 toxicities reported during cycle 1 . The toxicities reported across all cycles of treatment regardless of attribution are presented in Table 2.

Three patients, all treated at the $50 \mathrm{mg}$ dose of alisertib, experienced severe toxicities during the course of treatment. Two patients presented with treatment-related grade 4 neutropenia with grade 3 leukopenia. One patient presented with grade 4 hypertension and grade 3 hypoxia and dyspnea, all considered unlikely related to treatment. There was limited evidence of cumulative toxicity in the most frequently observed adverse events.

With regard to alopecia, one patient had complete hair loss at the time of enrollment, and she experienced regrowth of her hair during therapy. Each of the 6 patients who had no hair loss at study entry experienced hair loss with treatment: $\leq 10 \%$ (1 patient), 11-30\% (1 patient), 31-75\% (2 patients), and $>75 \%$ ( 2 patients). Two patients with $\leq 10 \%$

Table 2 Grade $\geq 2$ adverse events during all treatment cycles regardless of attribution

\begin{tabular}{|c|c|c|c|}
\hline \multirow[t]{2}{*}{ Toxicity } & \multicolumn{3}{|l|}{ Grade } \\
\hline & 2 & 3 & 4 \\
\hline \multicolumn{4}{|c|}{ Hematologic adverse events } \\
\hline Anemia & $2(22.2 \%)$ & 0 & 0 \\
\hline Leukopenia & $1(11.1 \%)$ & $2(22.2 \%)$ & 0 \\
\hline Lymphopenia & $1(11.1 \%)$ & $1(11.1 \%)$ & 0 \\
\hline Neutropenia & $2(22.2 \%)$ & 0 & $2(22.2 \%)$ \\
\hline \multicolumn{4}{|c|}{ Non-hematologic adverse events } \\
\hline Alopecia & $4(44.4 \%)$ & 0 & 0 \\
\hline Anxiety & $1(11.1 \%)$ & 0 & 0 \\
\hline Depression & $1(11.1 \%)$ & 0 & 0 \\
\hline Diarrhea & $2(22.2 \%)$ & 0 & 0 \\
\hline Dry mouth & $1(11.1 \%)$ & 0 & 0 \\
\hline Dyspnea & 0 & $1(11.1 \%)$ & 0 \\
\hline Fatigue & $2(22.2 \%)$ & $1(11.1 \%)$ & 0 \\
\hline Hypertension & 0 & 0 & $1(11.1 \%)$ \\
\hline Hypoxia & 0 & $1(11.1 \%)$ & 0 \\
\hline Insomnia & $1(11.1 \%)$ & 0 & 0 \\
\hline Nausea & $1(11.1 \%)$ & 0 & 0 \\
\hline $\begin{array}{l}\text { Nervous system } \\
\text { disorder-leg cramp }\end{array}$ & $1(11.1 \%)$ & 0 & 0 \\
\hline Oral mucositis & $1(11.1 \%)$ & 0 & 0 \\
\hline Tremor & $1(11.1 \%)$ & 0 & 0 \\
\hline
\end{tabular}

hair loss at study entry had $31-75 \%$ and $>75 \%$ hair loss with treatment, respectively.

\section{Clinical activity}

Three of the 9 evaluable patients enrolled had measurable disease. They included a 61-year-old woman with lobular $\mathrm{ER}+/ \mathrm{PR}+/ \mathrm{HER} 2$-breast cancer that had metastasized to the liver and bone who enrolled at the $50 \mathrm{mg}$ dose level and had a partial response lasting 11.1 months; a 53-year-old woman with lobular ER+/PR+/HER2-breast cancer that had metastasized to the bone, distant nodes, abdomen, and ovary who enrolled at the $50 \mathrm{mg}$ dose level and had a partial response lasting 25.9 months; and a 59-year-old woman with ductal ER+/PR+/HER2-breast cancer that had metastasized to the bone, distant nodes, abdomen, liver, and lung who enrolled at the $40 \mathrm{mg}$ dose level who had stable disease lasting 3.8 months.

There were 6 patients with non-measurable disease. One of 2 patients with non-measurable disease enrolled at the $40 \mathrm{mg}$ dose level and all 4 patients with non-measurable disease enrolled at the $50 \mathrm{mg}$ dose level maintained stable disease at least 6 months. Notably, a 51-year-old woman with fulvestrant-resistant, ER+/PR+/HER2-breast cancer that had metastasized to the bone treated at the $40 \mathrm{mg}$ dose level experienced a dramatic decline in FDG activity (a)

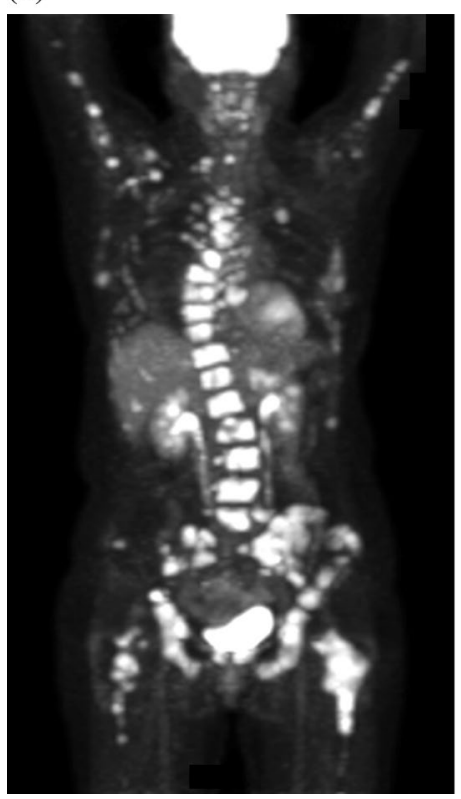

(b)

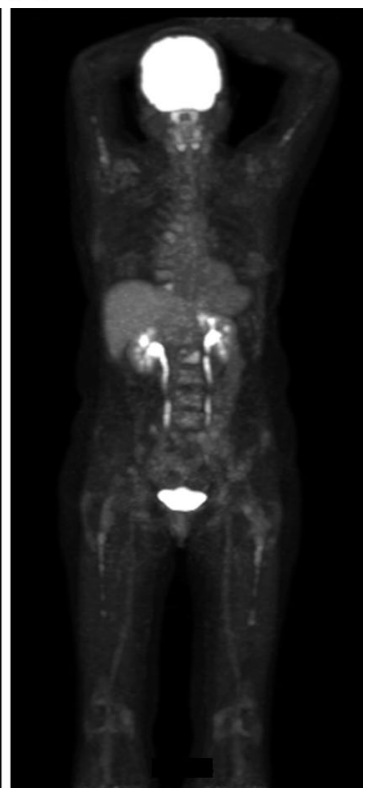

Fig. 1 Antitumor activity of alisertib and fulvestrant in a patient with prior progression during five different lines of endocrine therapy for metastatic disease, including tamoxifen, letrozole, fulvestrant, exemestane plus everolimus, and Z-endoxifen (on phase I trial): a baseline before starting alisertib and fulvestrant, and $\mathbf{b}$ after 2 cycles of treatment 
Fig. 2 Progression-free survival distribution

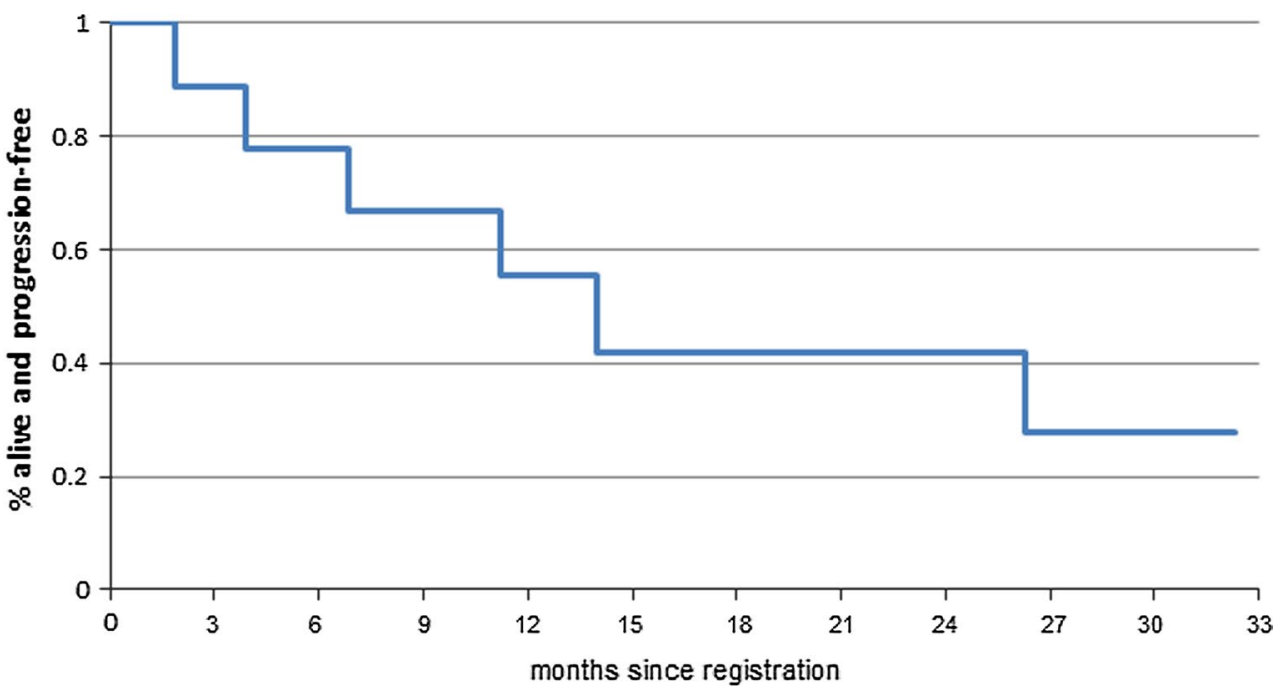

of her disease by PET CT imaging after 2 cycles of treatment (Fig. 1). This was further corroborated by a decline in her CA 15-3 tumor marker from 821 to $126 \mathrm{U} / \mathrm{mL}$, and she maintained stable disease for 13.8 months.

Thus, the 6-month CBR was 77.8\% (95\% CI 40.0-87.2\%).

\section{Clinical outcome}

There is one patient enrolled on $50 \mathrm{mg}$ dose level who continues on study treatment with stable disease at cycle 35 (31.2 months). Another patient enrolled on $50 \mathrm{mg}$ dose level discontinued study treatment after 14 cycles due to grade 4 hypertension with grade 3 dyspnea and hypoxia (all considered unlikely related to treatment); she remains alive without disease progression on fulvestrant. The remaining 7 patients have all discontinued treatment due to disease progression, and three of these patients have subsequently died. The one-year PFS rate is $55.6 \%$ (95\% CI 31.0-99.7\%) with a median PFS time of 12.4 months (95\% CI 5.3-not met) (Fig. 2). The treatment course, grade 3 or higher toxicities, and clinical outcomes of each of the 9 evaluable patients are summarized by dose level in Table 3 .

\section{Discussion}

Given the previously observed promising single-agent activity of alisertib in heavily pre-treated, endocrineresistant advanced breast cancer [26] and preclinical studies demonstrating enhanced antitumor activity when combined with fulvestrant $[14,15]$, we performed a phase I study that demonstrated alisertib $50 \mathrm{mg}$ twice daily on days $1-3,8-10$, and $15-17$ of a 28 -day cycle in combination with fulvestrant was clearly tolerable, and it is the

Table 3 Treatment course and outcome

\begin{tabular}{|c|c|c|c|c|}
\hline Alisertib dose level & Patient & $\geq$ grade 3 toxicity, all cycles & $\begin{array}{l}\text { Progression-free } \\
\text { survival (months) }\end{array}$ & $\begin{array}{l}\text { Overall } \\
\text { survival } \\
\text { (months) }\end{array}$ \\
\hline \multirow[t]{3}{*}{$40 \mathrm{mg}$} & 1 & None & 3.8 & 19.2 \\
\hline & 2 & None & 13.8 & 31.5 \\
\hline & 3 & None & 32.5 & $32.5+$ \\
\hline \multirow[t]{6}{*}{$50 \mathrm{mg}$} & 1 & None & 1.8 & 6.4 \\
\hline & 2 & Grade 4 neutropenia with grade 3 leukopenia and lymphopenia & 6.7 & $7.6+$ \\
\hline & 3 & None & 11.1 & $11.7+$ \\
\hline & 4 & $\begin{array}{l}\text { Grade } 3 \text { fatigue and then grade } 4 \text { hypertension with grade } 3 \text { dysp- } \\
\text { nea and hypoxia }\end{array}$ & $13.3+^{\mathrm{a}}$ & $13.3+$ \\
\hline & 5 & None & 25.9 & 27.6 \\
\hline & 6 & Grade 4 neutropenia with grade 3 leukopenia & $31.8+$ & $31.8+$ \\
\hline
\end{tabular}

${ }^{\text {a }}$ One subject discontinued study participation due to grade 4 hypertension with grade 3 dyspnea and hypoxia (considered unlikely related to treatment) after 13.3 months of therapy. As of the data lock, the patient had maintained stable disease on fulvestrant monotherapy 
RP2D when this alisertib schedule is utilized with fulvestrant for evaluation in future trials. We did not pursue higher alisertib dose levels as previous studies with the 21-day schedule showed substantial toxicity above the $50 \mathrm{mg}$ dose level.

Hematologic toxicity grade $\geq 3$ was not observed during cycle one. Across all cycles, it was limited to two grade 3 leukopenia and two grade 4 neutropenia events in two patients $(n=2,22 \%)$. Grade $1-2$ anemia was common; however, there were no grade $\geq 3$ events. Grade 3 gastrointestinal toxicities were not observed, and low-grade nausea and vomiting were uncommon. Importantly, there was only a single episode of grade 2 oral mucositis $(n=1,11 \%)$ and no grade $\geq 3$ events. These findings are notable given that stomatitis and neutropenia were common DLTs during alisertib development. Specifically, in breast cancer patients receiving alisertib monotherapy (50 $\mathrm{mg}$ dose on days $1-7$ of a 21-day cycle), the grade 1-2 stomatitis event rate was $30 \%$, grade $3-4$ stomatitis event rate was $15 \%$, and grade 3-4 neutropenia rate was $57 \%$. The pulse dose, 28 -day schedule of alisertib utilized in this trial resulted in significantly lower grade $\geq 3$ event rates relative to those observed in prior studies with the traditional 21-day cycle of alisertib. There was limited evidence of cumulative toxicity in the most frequently observed adverse events.

Striking clinical activity was observed for the combination of alisertib and fulvestrant in patients with secondary endocrine resistance. The 6-month CBR of $78 \%$ is an important finding given that all patients had received prior aromatase inhibitor and two-thirds prior fulvestrant. These data provide support to the working hypothesis that alisertib restores endocrine sensitivity. The objective response rate to this combination remains to be defined due to the fact the majority of the patients had non-measurable disease at enrollment; it is notable, however, that 2 of 3 patients with measurable disease had a partial response to therapy.

The median PFS was 12.4 months. Six (67\%) patients received $\geq 12$ cycles of therapy, including one patient who remains on active treatment after 31 months. This PFS time is longer than the median PFS of 7.9 months observed in a similar patient population (ER+, endocrine-resistant) receiving alisertib monotherapy [26]. Both of these median PFS times exceed what has been typically observed in secondline endocrine therapy trials in which the median PFS has varied between 2.8 and 4.6 months [31, 32]; however, it is noteworthy that in a similar patient population treated in MONARCH-2, median PFS for the fulvestrant/placebo arm was 9.3 months [33]. Nonetheless, both CBR and PFS times are in the range of recently FDA-approved combinations of targeted agents with endocrine therapy [32, 34, 35]. As such, these promising efficacy results and the favorable toxicity profile observed in this study have led to the development and activation of a phase II evaluation of alisertib alone and in combination with fulvestrant in endocrine-resistant metastatic breast cancer (NCT02860000; TBCRC041).

Despite many strengths of this trial, the authors acknowledge its limitations. The study sample size is small. While sufficient to address the primary endpoint, the substantial efficacy and tolerability of this regimen observed in our study need to be confirmed in subsequent clinical trials powered for survival endpoints. In addition to this, pharmacokinetic studies were not incorporated into the study design. Given that lower rates of well-established dose-limiting toxicities were observed in this trial with the pulse dose alisertib regimen, it is feasible that patients may have had lower drug levels enabling the more favorable toxicity profile. It is also feasible that there was a drug interaction between fulvestrant and alisertib facilitating exposure to lower alisertib concentrations. Finally, while archived tumor biospecimens were collected from 7 of 9 patients, a mix of primary and metastatic tumors were retrieved. Given this heterogeneity and the small and incomplete sample size, the correlative biomarker results were not included in this manuscript.

In conclusion, the combination of alisertib and fulvestrant is tolerable with limited grade $\geq 3$ adverse events relative to what has been observed in prior phase II studies with alisertib. In addition to this, the regimen appears to be highly effective even among those with secondary endocrine resistance and previously treated with chemotherapy. The clinical activity observed when the majority of patients had prior progression on fulvestrant is consistent with preclinical data that suggest alisertib can target endocrine-resistant $\mathrm{ER}^{\mathrm{low} /-}$ breast tumor-initiating cells and restore endocrine sensitivity. Further evaluation of alisertib in combination with fulvestrant is warranted and indeed ongoing.

Acknowledgements This clinical trial was supported by Takeda Oncology, manufacturer of alisertib. This publication was supported by the NIH Grant K12 CA90628 [TCH] and by the CTSA Grant UL1 TR000135 [TCH] from the National Center for Advancing Translational Sciences (NCATS), a component of the NIH. Its contents are solely the responsibility of the authors and do not necessarily represent the official views of the National Institutes of Health.

Funding This study was funded by Takeda Oncology, NIH Grant K12 CA90628 [TCH] and by the CTSA Grant UL1 TR000135 [TCH] from the National Center for Advancing Translational Sciences (NCATS), a component of the NIH.

\section{Compliance with ethical standards}

Conflict of interest Dr. Goetz has received research funding Pfizer, Lilly, and Myriad and is a consultant/advisory board member for Lilly, Biotheranostics, and Myriad. Dr. Opyrchal received research funding from Pfizer. The other authors declare no conflict of interest. 
Ethical approval All procedures performed in studies involving human participants were in accordance with the ethical standards of the institutional and/or national research committee and with the 1964 Helsinki declaration and its later amendments or comparable ethical standards.

Informed consent Informed consent was obtained from all individual participants included in the study.

Open Access This article is distributed under the terms of the Creative Commons Attribution 4.0 International License (http://creativecomm ons.org/licenses/by/4.0/), which permits unrestricted use, distribution, and reproduction in any medium, provided you give appropriate credit to the original author(s) and the source, provide a link to the Creative Commons license, and indicate if changes were made.

\section{References}

1. Ferlay J, Soerjomataram I, Dikshit R, Eser S, Mathers C, Rebelo M, Parkin DM, Forman D, Bray F (2015) Cancer incidence and mortality worldwide: sources, methods and major patterns in GLOBOCAN 2012. Int J Cancer 136(5):E359-E386

2. Dowsett M, Forbes JF, Bradley R, Ingle J, Aihara T, Bliss J, Boccardo F, Coates A, Coombes RC, Cuzick J et al (2015) Aromatase inhibitors versus tamoxifen in early breast cancer: patient-level meta-analysis of the randomised trials. Lancet 386(10001):1341-1352

3. Pan H, Gray R, Braybrooke J, Davies C, Taylor C, McGale P, Peto R, Pritchard KI, Bergh J, Dowsett M, Hayes DF, EBCTCG (2017) 20 -year risks of breast-cancer recurrence after stopping endocrine therapy at 5 years. N Engl J Med 377:1836-1846

4. Osborne CK, Schiff R (2011) Mechanisms of endocrine resistance in breast cancer. Annu Rev Med 62:233-247

5. Ring A, Dowsett M (2004) Mechanisms of tamoxifen resistance. Endocr Relat Cancer 11(4):643-658

6. Johnston SR, Saccani-Jotti G, Smith IE, Salter J, Newby J, Coppen M, Ebbs SR, Dowsett M (1995) Changes in estrogen receptor, progesterone receptor, and $\mathrm{pS} 2$ expression in tamoxifen-resistant human breast cancer. Cancer Res 55(15):3331-3338

7. Kuukasjarvi T, Kononen J, Helin H, Holli K, Isola J (1996) Loss of estrogen receptor in recurrent breast cancer is associated with poor response to endocrine therapy. J Clin Oncol 14(9):2584-2589

8. Gutierrez MC, Detre S, Johnston S, Mohsin SK, Shou J, Allred DC, Schiff R, Osborne CK, Dowsett M (2005) Molecular changes in tamoxifen-resistant breast cancer: relationship between estrogen receptor, HER-2, and p38 mitogen-activated protein kinase. J Clin Oncol 23(11):2469-2476

9. Lindstrom LS, Karlsson E, Wilking UM, Johansson U, Hartman J, Lidbrink EK, Hatschek T, Skoog L, Bergh J (2012) Clinically used breast cancer markers such as estrogen receptor, progesterone receptor, and human epidermal growth factor receptor 2 are unstable throughout tumor progression. J Clin Oncol 30(21):2601-2608

10. Mani SA, Guo W, Liao MJ, Eaton EN, Ayyanan A, Zhou AY, Brooks M, Reinhard F, Zhang CC, Shipitsin M et al (2008) The epithelial-mesenchymal transition generates cells with properties of stem cells. Cell 133(4):704-715

11. Hwang-Verslues WW, Kuo WH, Chang PH, Pan CC, Wang HH, Tsai ST, Jeng YM, Shew JY, Kung JT, Chen CH et al (2009) Multiple lineages of human breast cancer stem/progenitor cells identified by profiling with stem cell markers. PLoS ONE 4(12):e8377

12. Kemper K, de Goeje PL, Peeper DS, van Amerongen R (2014) Phenotype switching: tumor cell plasticity as a resistance mechanism and target for therapy. Cancer Res 74(21):5937-5941
13. Pece S, Tosoni D, Confalonieri S, Mazzarol G, Vecchi M, Ronzoni S, Bernard L, Viale G, Pelicci PG, Di Fiore PP (2010) Biological and molecular heterogeneity of breast cancers correlates with their cancer stem cell content. Cell 140(1):62-73

14. D'Assoro AB, Liu T, Quatraro C, Amato A, Opyrchal M, Leontovich A, Ikeda Y, Ohmine S, Lingle W, Suman V et al (2014) The mitotic kinase Aurora-a promotes distant metastases by inducing epithelial-to-mesenchymal transition in ERalpha(+) breast cancer cells. Oncogene 33(5):599-610

15. Opyrchal M, Salisbury JL, Zhang S, McCubrey J, Hawse J, Goetz MP, Lomberk GA, Haddad T, Degnim A, Lange C et al (2014) Aurora-A mitotic kinase induces endocrine resistance through down-regulation of ERalpha expression in initially ERalpha+ breast cancer cells. PLoS ONE 9(5):e96995

16. Daly AC, Randall RA, Hill CS (2008) Transforming growth factor beta-induced Smad1/5 phosphorylation in epithelial cells is mediated by novel receptor complexes and is essential for anchorageindependent growth. Mol Cell Biol 28(22):6889-6902

17. Bharathy S, Xie W, Yingling JM, Reiss M (2008) Cancer-associated transforming growth factor beta type II receptor gene mutant causes activation of bone morphogenic protein-Smads and invasive phenotype. Cancer Res 68(6):1656-1666

18. Huang YH, Luo MH, Ni YB, Tsang JY, Chan SK, Lui PC, Yu AM, Tan PH, Tse GM (2014) Increased SOX2 expression in less differentiated breast carcinomas and their lymph node metastases. Histopathology 64(4):494-503

19. Vazquez-Martin A, Cufi S, Lopez-Bonet E, Corominas-Faja B, Cuyas E, Vellon L, Iglesias JM, Leis O, Martin AG, Menendez JA (2013) Reprogramming of non-genomic estrogen signaling by the stemness factor SOX2 enhances the tumor-initiating capacity of breast cancer cells. Cell Cycle 12(22):3471-3477

20. Creighton CJ, Li X, Landis M, Dixon JM, Neumeister VM, Sjolund A, Rimm DL, Wong H, Rodriguez A, Herschkowitz JI et al (2009) Residual breast cancers after conventional therapy display mesenchymal as well as tumor-initiating features. Proc Natl Acad Sci USA 106(33):13820-13825

21. Thrane S, Pedersen AM, Thomsen MB, Kirkegaard T, Rasmussen BB, Duun-Henriksen AK, Laenkholm AV, Bak M, Lykkesfeldt AE, Yde CW (2015) A kinase inhibitor screen identifies Mcl-1 and Aurora kinase A as novel treatment targets in antiestrogenresistant breast cancer cells. Oncogene 34(32):4199-4210

22. Hole S, Pedersen AM, Lykkesfeldt AE, Yde CW (2015) Aurora kinase $\mathrm{A}$ and $\mathrm{B}$ as new treatment targets in aromatase inhibitor-resistant breast cancer cells. Breast Cancer Res Treat 149(3):715-726

23. Siggelkow W, Boehm D, Gebhard S, Battista M, Sicking I, Lebrecht A, Solbach C, Hellwig B, Rahnenfuhrer J, Koelbl H et al (2012) (2012): expression of aurora kinase A is associated with metastasis-free survival in node-negative breast cancer patients. BMC Cancer 12:562

24. Friedberg JW, Mahadevan D, Cebula E, Persky D, Lossos I, Agarwal AB, Jung J, Burack R, Zhou X, Leonard EJ et al (2014) Phase II study of alisertib, a selective Aurora A kinase inhibitor, in relapsed and refractory aggressive $\mathrm{B}$ - and T-cell non-Hodgkin lymphomas. J Clin Oncol 32(1):44-50

25. Dees EC, Cohen RB, von Mehren M, Stinchcombe TE, Liu H, Venkatakrishnan K, Manfredi M, Fingert H, Burris HA 3rd, Infante JR (2012) Phase I study of aurora A kinase inhibitor MLN8237 in advanced solid tumors: safety, pharmacokinetics, pharmacodynamics, and bioavailability of two oral formulations. Clin Cancer Res 18(17):4775-4784

26. Melichar B, Adenis A, Lockhart AC, Bennouna J, Dees EC, Kayaleh O, Obermannova R, DeMichele A, Zatloukal P, Zhang B et al (2015) Safety and activity of alisertib, an investigational aurora kinase A inhibitor, in patients with breast cancer, small-cell lung cancer, non-small-cell lung cancer, head and neck squamous-cell 
carcinoma, and gastro-oesophageal adenocarcinoma: a five-arm phase 2 study. Lancet Oncol 16(4):395-405

27. Huck JJ, Zhang M, Mettetal J, Chakravarty A, Venkatakrishnan K, Zhou X, Kleinfield R, Hyer ML, Kannan K, Shinde V et al (2014) Translational exposure-efficacy modeling to optimize the dose and schedule of taxanes combined with the investigational Aurora A kinase inhibitor MLN8237 (alisertib). Mol Cancer Ther 13(9):2170-2183

28. Le KN, Yu L, Manfredi M, Ecsedy J, Silverman L, Cardoza K, Shyu W (2011) Evaluation of optimal dosing regimens for investigational drug MLN8237, an aurora A kinase inhibitor, in combination with docetaxel through pharmacokinetic-pharmacodynamic (PK-PD) modeling of hematological toxicity. Clin Pharmacol Ther 89:S58-S59 (suppl; abstr PII-67)

29. World Health Organization (1979) WHO handbook for reporting results of cancer treatment. World Health Organization, Geneva. http://apps.who.int/iris/handle/10665/37200

30. Cardoso F, Costa A, Senkus E, Aapro M, Andre F, Barrios CH, Bergh J, Bhattacharyya G, Biganzoli L, Cardoso MJ et al (2017) 3rd ESO-ESMO international consensus guidelines for advanced breast cancer (ABC 3). Ann Oncol 28(1):16-33

31. Johnston SR, Kilburn LS, Ellis P, Dodwell D, Cameron D, Hayward L, Im YH, Braybrooke JP, Brunt AM, Cheung KL et al (2013) Fulvestrant plus anastrozole or placebo versus exemestane alone after progression on non-steroidal aromatase inhibitors in postmenopausal patients with hormone-receptor-positive locally advanced or metastatic breast cancer (SoFEA): a composite, multicentre, phase 3 randomised trial. Lancet Oncol 14(10):989-998

32. Baselga J, Campone M, Piccart M, Burris HA 3rd, Rugo HS, Sahmoud T, Noguchi S, Gnant M, Pritchard KI, Lebrun F et al (2012) Everolimus in postmenopausal hormone-receptor-positive advanced breast cancer. N Engl J Med 366(6):520-529

33. Sledge GW Jr, Toi M, Neven P, Sohn J, Inoue K, Pivot X, Burdaeva O, Okera M, Masuda N, Kaufman PA et al (2017) MONARCH 2: abemaciclib in combination with fulvestrant in women with HR+/HER2-advanced breast cancer who had progressed while receiving endocrine therapy. J Clin Oncol 35(25):2875-2884

34. Yardley DA, Ismail-Khan RR, Melichar B, Lichinitser M, Munster PN, Klein PM, Cruickshank S, Miller KD, Lee MJ, Trepel JB (2013) Randomized phase II, double-blind, placebo-controlled study of exemestane with or without entinostat in postmenopausal women with locally recurrent or metastatic estrogen receptor-positive breast cancer progressing on treatment with a nonsteroidal aromatase inhibitor. J Clin Oncol 31(17):2128-2135

35. Turner NC, Ro J, Andre F, Loi S, Verma S, Iwata H, Harbeck N, Loibl S, Huang Bartlett C, Zhang K et al (2015) Palbociclib in hormone-receptor-positive advanced breast cancer. N Engl J Med 373(3):209-219 